\section{Smoking and Pregnancy}

SrR,--Your invitation for Dr Yerushalmy to respond to your editorial ${ }^{1}$ to the correspondence on smoking during pregnancy arrived a few days after his death. Dr Yerushalmy would have enjoyed contributing to the discussions which centred around the two propositions that he described ${ }^{2}$ : that cigarette smoking acts as an exogenous factor which interferes with the intrauterine growth and development of the foetus and that smokers may represent a group of people whose reproductive experience would have duplicated the observed pattern whether or not they smoked.

His study on 'Infants with Low Birth Weight Born Before Their Mothers Started to Smoke' ${ }^{3}$ seems to support the hypothesis that the higher incidence of low-birth-weight infants is due to the smoker, not the smoking. Dr Yerushalmy would probably have made a strong plea, as he did in his paper, to repeat this study on larger samples in other population groups to get a definite verdict on the alternative hypothesis. This could be done by asking large numbers of pregnant women who smoke when they started to smoke, what was the birth weight and the health data of previously born children.

\section{Yours faithfully, \\ BEA J. VAN DEN BERG}

Child Health and Development Studies, School of Public Health,

University of California, Berkeley,

3867 Howe Street,

Oakland, California 94611

${ }^{1}$ Nature, 245, 61 (1973).

2Yerushalmy, J., Proc. 6th Berkeley Symp. Math. Statistics Probability, IV, 329 (1972). ${ }^{3}$ Yerushalmy, J., Am. J. Obstet. Gynec., 112, 2 (1972).

\section{Smoking, Pregnancy and Publicity}

SıR,--Professor Burch ${ }^{1}$ and Dr Hickey et $a l^{2}$ rely heavily on the publications of the late Professor Yerushalmy to criticise my own remarks. As there still seems to be some confusion about the value of his statistical evidence, I would like to elaborate a little on the points I made in my earlier letter.

First, estimates of the mean difference in birthweight between babies of smokers and non-smokers do, of course, differ, but are all in the 150 to $250 \mathrm{~g}$ range, and the exact value for a particular population is not relevant to the argument. Yerushalmy's test for a shift of $200 \mathrm{~g}$ in the mean of the birthweight distributions of babies of smokers is inappropriate.

What he should have tested for was an equivalence of the distributions apart from a shift in mean value, which is estimated from the data and need not be exactly $200 \mathrm{~g}$. As Dr James ${ }^{5}$ has shown, however, we will still find a reversal in mortality rates in the babies weighing $2,500 \mathrm{~g}$ or less, if a given percentage reduction in birthweight due to smoking is assumed, rather than a constant absolute reduction. Moreover, a simple study of the two birthweight distributions, in Yerushalmy's own study for example ${ }^{6}$, reveals quite clearly how an increased mortality among babies of smokers which is associated with a reduction in birthweight will lead to a lower mortality among babies of smokers if only the babies weighing $2,500 \mathrm{~g}$ or less are studied. For this reason all of Yerushalmy's analyses of babies weighing $2,500 \mathrm{~g}$ or less are irrelevant to the main issue.

Professor Burch quotes Yerushalmy's claim that there is no association between birthweight and age for mothers less than twenty-five years old. There are, however, studies other than Professor Yerushalmy's and with much larger numbers ${ }^{7,8}$ which do show that the proportion of low birthweight babies born to women under twenty is about $20 \%$ higher than that for women aged between twenty and twenty-four. Until due allowance is made for this, Yerushalmy's conclusions should not be accepted at their face value.

As Professor Burch observes, I am quite happy to "concede" that the scientific case for a causal relationship is not yet completely conclusive and among other possibilities we need to investigate the 'constitutional' hypothesis. The point at issue, however, is how the available evidence should be assessed, and what publicity should be given to any conclusions.

An impartial observer, it seems to me, would have little doubt that this evidence justifies efforts aimed at persuading pregnant women to stop smoking. Your correspondents, I suggest. have confused this practical, ethical issue with the other problem of scientific proof.

\section{Yours faithfully, \\ HARVEY GOLDSTEIN}

National Children's Bureau,

8 Wakley Street, Islington,

London, ECIV $7 Q E$

1 Burch, P. R. J., Nature, 246, 177 (1973).

2 Hickey, R. J., Boycc, D. E., and Clelland, R. C. Nature, 246, 177 (1973).

${ }^{3}$ Goldstein, H., Nature, 245, 467 (1973).

4 Yerushalmy, J., Am. J. Obstet. Gynec., 114,571 (1972).

5 James, W. H., Nature, 246, 235 (1973)

6 Yerushalmy, J., Am.J. Epidemiol., 93, 443 (1971).

${ }^{7}$ Butler, N. R., and Alberman, E. D., Perinatal Problems (Livingstone, Edinburgh, 1969).

8 Chase, H. C, and Byrnes, M. E., Vital and Health Statistics Series 3, 15 (National Centre for Health Studies, Rockville, Maryland, 1972)

This correspondence is now closed.-ED.

\section{Literature Citations}

SrR,-The transcription of literature citations in scientific articles is rendered unnecessarily tedious by the diversity of arbitrary conventions adopted by different journals. References jotted down for subsequent bibliographical use must be differently transcribed according to the journal in which they are to appear. The differences are matters of form and style as well as of completeness.

We are writing to urge that commissions of editors convene information retrieval specialists, typographers, and some common readers to draw up broadly acceptable conventions that optimise clarity and simplicity in literature citations.

Some specific suggestions are: (1) Each scientific journal should adopt an abbreviation, if necessary, of its original or transliterated title that can be used without confusion anywhere in the scientific literature. The abbreviations of common words such as 'Annual' and 'Comptes Rendues' should be uniform. Local conventions such as the germanic use of lower case for adjectives or special self-reference terms ("This Journal") are to be avoided. (2) The presentation of author's names, initials, publication year, article title and key-words, volume number and pagination should be standardised as to sequence, punctuation and type font. Simplifications should be accomplished by deletions without rearrangement. (3) The title page of articles should bear the com. plete article reference as it should be cited. Fascicule numbers, issue dates and so on, not normally cited, should appear separately on the page if they serve a function for particular users.

The temporary inconvenience to journal staff in changing habits would be offset, in the long run, by diminished editorial labour in the revision of improperly submitted bibliographies.

Uniformity in these matters would cause little reduction in the marvellous particularity of individual journals and would reduce the burden on authors, readers, and especially secretaries.

Yours faithfully,

Michael Yarmolinsky

Marie-JoËlle HoOgVeld-Lepasteur

Institut de Biologie Moléculaire, Université Paris VII, Tour 43.

2, Place Jussieu, 75005 Paris

\section{Bomb Disposal}

SIR,-Disarming and removing explosive devices is dangerous to police and army personnel, and also to the general public. I would like to propose a 